\title{
"ESTA OBRA SUBLIME ES LA SEÑAL DE UN GRAN REY»: LA CIUDAD-ARSENAL DE FERROL O EL SUEÑO PORTUARIO DEL MARQUÉS DE LA ENSENADA $(1747-1754)^{*}$
}

\author{
"This Sublime Work is the Mark of a Great King": \\ The City/Arsenal of Ferrol or The Marquis de la \\ Ensenada's Vision of A Naval Port (1747-1754)
}

\author{
Alfredo VIGO TRASANCOS \\ Universidad de Santiago de Compostela \\ alfredomanuel.vigo@usc.es
}

Fecha de recepción: 10/01/2016

Fecha de aceptación: 13/10/2016

RESUMEN: Durante el mandato ministerial del marqués de la Ensenada se empezó a construir en la villa de Ferrol, con la aprobación del rey Fernando VI, el puerto de guerra más importante de España, obra en la que se gastaron sumas ingentes de dinero, en la que intervinieron destacadas personalidades de su tiempo y que dio forma a un magnífico arsenal de marina. Fue, sin duda, un proyecto arquitectónico e hidráulico de carácter excepcional que debe ser considerado entre los más importantes en su género de los llevados a cabo en la Europa del siglo XVIII.

Palabras clave: Ferrol; Arsenal de Marina; marqués de la Ensenada; siglo XVIII; Arquitectura; Fernando VI; Ilustración.

* Este artículo se integra en el proyecto de investigación titulado Memoria, textos e imágenes. La recuperación del patrimonio perdido para la sociedad de Galicia, concedido por el Ministerio de Economía y Competitividad, para el trienio 2015-2017, y que tiene código de referencia HAR2014-53893-R. 
ABSTRACT: It was during the Marquis de la Ensenada's premiership that construction of the largest naval base in the kingdom of Spain began in the city of Ferrol, with the approval of King Ferdinand VI. Huge sums of money were invested in the undertaking, one in which several leading figures of the day took part and which gave shape to a magnificent naval arsenal. It was, without question, an outstanding architectural and hydraulic engineering project that should be regarded as one of the most important of its kind to be carried out in 18th-century Europe.

Key words: Ferrol; naval arsenal; the Marquis de la Ensenada; 18th century; architecture; Ferdinand VI; the Enlightenment.

Pero por una anomalía o contradicción extraordinaria del espíritu humano, este hombre [Ensenada] religioso, modesto y desinteresado, gustaba de la magnificencia y del lujo en su persona y trato; hasta un punto que ya tocaba en extravagancia. Sus camisas se cosían y planchaban en Paris. El día de corte o de gala se presentaba en Palacio con más cruces, diamantes, condecoraciones y cordones que ningún Grande de España. Valuábase entonces en 500.000 duros lo que llevaba en su persona. Cuéntase que en cierto día le manifestó el rey su sorpresa al ver el subido precio de sus adornos, y que el Marqués le contestó: «Señor, por la librea del criado se ha de conocer la grandeza del amo».

Martín Fernández de Navarrete, Estado general de la Armada del año $1829^{1}$

Con independencia de la opinión, casi siempre positiva, que la mayor parte de los historiadores hayan podido tener con respecto a la figura política del marqués de la Ensenada ${ }^{2}$, en lo que existe una absoluta unanimidad es en señalar la extraña fascinación que don Zenón siempre manifestó por el lujo desmedido en su atuendo, como si quisiese expresar con él una imagen de opulencia que ocultase de ese modo lo humilde de su nacimiento. Y nada mejor para confirmar lo que decimos que contemplar el magnífico retrato que le hizo hacia 1750-1752 el pintor veneciano Jacopo Amiconi, con Ensenada en la cima de su poder, donde aparece

1. Cito por Pavía y Pavía, Francisco de Paula. Galería biográfica de los generales de Marina, jefes y personajes notables que figuraron en la misma corporación desde 1700 a 1868, I. Madrid: Imprenta de José López, 1873, p. 499.

2. Entre las muchas opiniones que pudieran escogerse para intentar perfilar en unas breves líneas la personalidad del ministro, creo que es muy clara la expresada por OzANAM, Didier. «El marqués de la Ensenada». En Bonet Correa, Antonio y Blasco Esquivias, Beatriz (comisarios). Un reinado bajo el signo de la paz. Fernando VI y Bárbara de Braganza 1746-1759. Madrid: Real Academia de Bellas Artes de San Fernando, 2003, p. 299; que dice lo siguiente: "Entre estos españoles "ilustrados”, ninguno ha tenido una visión más clara de los problemas en juego y de las soluciones mejor adaptadas a la coyuntura de la época que el marqués de la Ensenada. Su aproximación realista a los hechos, su pragmatismo de buena ley le colocan en una postura muy alejada de la de los arbitristas o de los teóricos de la política que abundan por entonces". 
el marqués vestido con el uniforme de gala de capitán general de la Armada recargado de faldones, amplias bocamangas, suntuosos rojos, ricos bordados y galones dorados; con su camisa y corbata llena de encajes; con su tricornio bajo el brazo ricamente engalanado; con su peluca larga y rizada a la moda del momento; y mirando al espectador resuelto y joven como un triunfador cargado de joyas, con todas las insignias más prestigiosas -Toisón de Oro, gran cruz de caballero de la Orden de Malta y lo que pudiera ser, quizá, la cruz de caballero de la Orden de San Genaro de Nápoles- ${ }^{3}$, y ante una mesa dorada, un gran cortinaje oscuro y con un fondo arquitectónico solemne, columnario, dórico y marítimo que proclamaba además su rango de superministro de Hacienda, Guerra, Marina e Indias (Fig. 1). Con razón dice Gómez Urdáñez que aparece Ensenada en el retrato casi como si fuera un "rey», tanta es la magnificencia y el esplendor con que se nos presenta ${ }^{4}$.

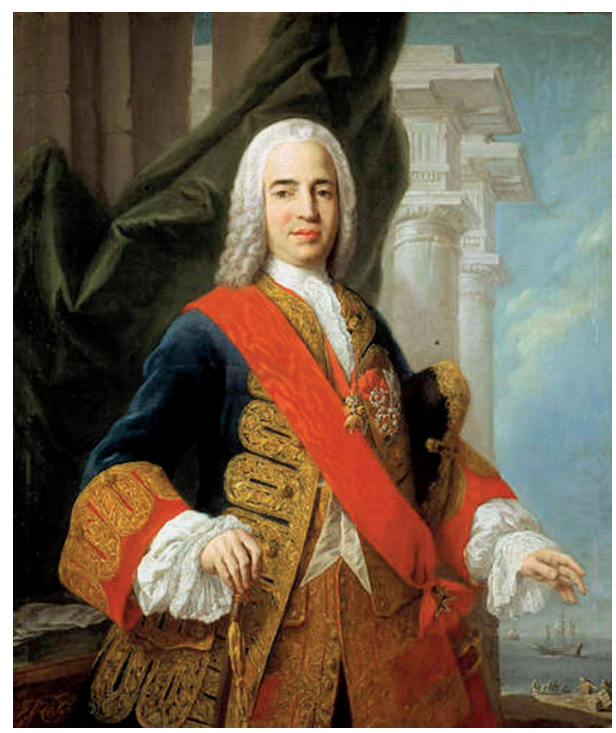

Figura 1. Retrato del marqués de la Ensenada. C. 1750-1752. Jacopo Amiconi. Museo Nacional del Prado.

3. Entre 1743 y 1750 recibió, en efecto, de los reyes muchos honores: Lugarteniente del Almirantazgo, el 24 de mayo de 1743; honores de Capitán General de la Armada y del Ejército, el 22 de noviembre de 1749; caballero del Toisón de Oro desde el 12 de abril de 1750, y caballero gran cruz de la orden de San Juan de Jerusalén (Malta) desde el 27 de octubre de 1750. Además había recibido los hábitos de la de Calatrava y de San Genaro en 1742, asimismo Notario Mayor de los Reinos, Consejero de Estado desde 1743, etc. Vid. ABAD LEÓn, Felipe. El marqués de la Ensenada. Logroño: Diputación Provincial, 1981, pp. 49-50.

4. Gómez UrdáÑez, José Luis. Carvajal-Ensenada: Un binomio político. Córdoba: Universidad de Córdoba, 2002, p. 15. 
No es gratuita esta introducción; viene al caso porque estoy convencido de que Ensenada creía firmemente en que la «imagen» era una cuestión cargada de símbolos que no debía ser en modo alguno despreciada. Es más, que pusiese tanto interés en decorarse con un aspecto tan suntuoso era una manera de identificarse con la Monarquía a la que representaba y que estaba encabezada por el propio rey. Fernando VI no era un soberano agraciado, tampoco particularmente inteligente ni trabajador y era además de tendencia melancólica, poco brillante en lo social y siempre preocupado por la impresión que tenían de él tanto el rey de Francia, por ejemplo, como el propio Papa, que consideraba que no le tenían la debida consideración ${ }^{5}$; por tanto, que Ensenada, como ministro del rey, mostrase en su apariencia una riqueza desmedida no era más que una manera de mostrarse como una brillante "pantalla" del monarca que expresaba así, a través de su ostentoso atuendo, una imagen de extraordinaria riqueza; justo la idea que el marqués tenía de lo que debía ser la Monarquía española: rica, militarmente respetada y poderosa, algo que el nada atrayente monarca difícilmente podía representar, pese al interés que tuvo Ensenada por "Construirlo» como el soberano restaurador de la grandeza española que tenía en Fernando el Católico y Felipe II sus principales modelos y hasta en el rey francés Luis $\mathrm{XIV}^{6}$, su bisabuelo, un referente inequívoco de "grandeur". En consecuencia, la frase que se le atribuye dirigida al rey cuando este le preguntó por qué se vestía con tanta riqueza: «Señor, por la librea del criado se ha de conocer la grandeza del amo", no ha de verse simplemente como una salida airosa llena de ingenio, sino como una respuesta eficaz a la par que bastante sincera que en cierto modo expresaba que su imagen iba asociada claramente con su idea del poder. Tal vez por ello no fue Ensenada amigo de lo pequeño, discreto o menor, de aquello que estaba llamado a pasar desapercibido. Su afán era deslumbrar a través de la magnificencia, y por ese motivo sus más importantes proyectos, que concebía siempre en representación del monarca, debían ser grandes y suntuosos y más aquellos que, como el arsenal de Ferrol, eran a sus ojos prioritarios y debían mostrar a nacionales y extranjeros que eran la obra «Sublime» «de un gran rey»".

5. Al respecto véase Gómez URdÁÑEZ, José Luis. Fernando VI. Madrid: Arlanza ediciones, 2001, especialmente pp. 40-42, 58-61 y 82 y ss.

6. Ibidem, p. 52.

7. Esta era la frase con la que comenzaba la inscripción latina que estuvo previsto colocar sobre la puerta principal del arsenal de Ferrol y que fue sustituida en 1783 por la que hoy existe. Aunque colocada en el reinado de Carlos III, en cierto modo exalta la gran obra iniciada por Fernando VI en la época de Ensenada. La inscripción completa era esta: «Hoc signum magni regis, est opus sublime. Si intro ingrediar, et magnifica tangar rate carina, navem, munitionesque, et omnia necessaria utiliter ad bellum suscipiendum ¡Felix Hispania! nimiumque felix! dum rex tan probidus generose imperat, gubernat, et protegit. Vivat Carolus III, et in aeternum vivat». La traducción, realizada libremente, sería más o menos la siguiente: "Aquí está la señal de un gran rey, es una obra sublime. Si vas por dentro te impresionarán las magníficas quillas de los navíos, las municiones y todo lo que es útil y necesario para afrontar la guerra. ¡Dichosa España! ¡Enormemente dichosa! Pues un rey tan bondadoso reina 


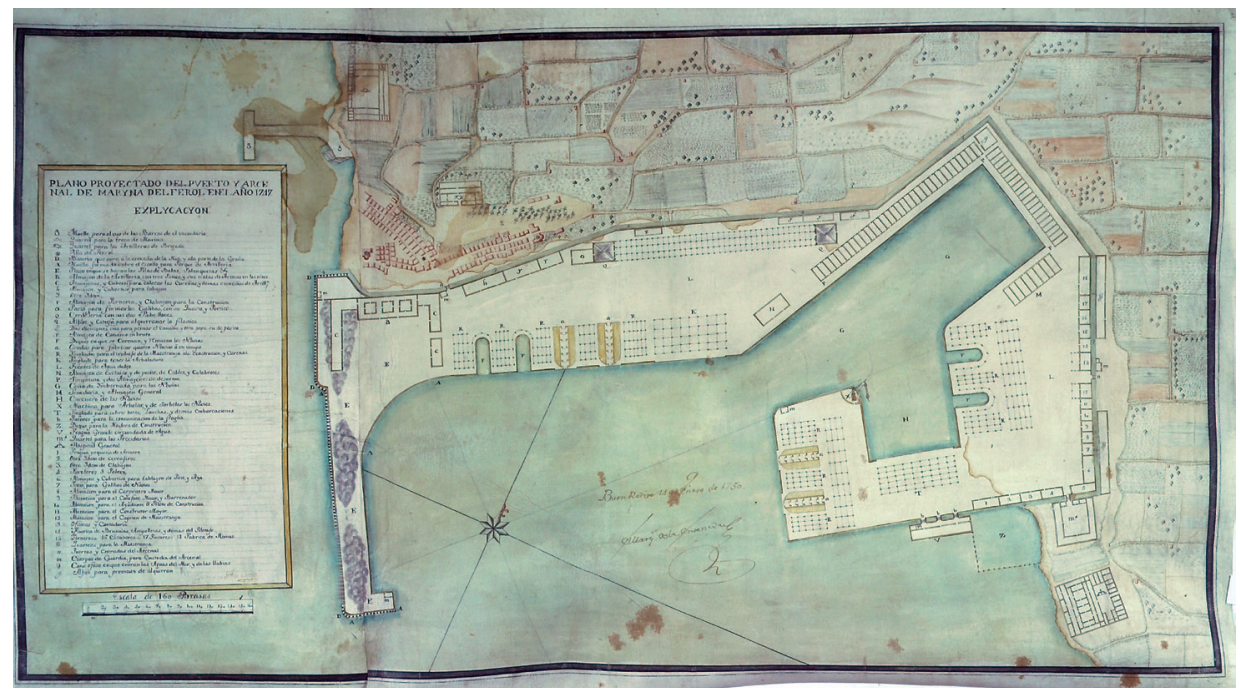

Figura 2. Proyecto de 1747 para el arsenal de Ferrol, aprobado el 14 de enero de 1750. Cosme Álvarez. Museo Naval de Madrid, P3-A-32.

Ahora bien, no fue la magnificencia sino el más estricto pragmatismo -Ensenada conocía perfectamente la ría de Ferrol por haber residido en ella como comisario entre 1730 y $1731-^{8}$ el que determinó al ministro a sugerir al monarca que era necesario trasladar el arsenal de A Graña -donde lo había dispuesto su antecesor Patiño- a la villa inmediata de Ferrol por considerarla más adecuada para el gran proyecto que albergaba. Sus enemigos quisieron vincular esta decisión del marqués al hecho de que había querido congraciarse con una amante que tenía en el entorno de la villa muchas propiedades terrenas; eso al menos es lo que nos dice, en 1774, el comandante del ejército británico el escocés William Dalrymple al hacer referencia a las instalaciones militares ferrolanas, si bien pronto se encarga de afirmar que era solo un infundio pues "como resulta evidente» el arsenal de

\footnotetext{
dignamente, gobierna y protege. ¡Viva Carlos III! ¡que viva eternamente!». Fue dada a conocer por ALONSO Y LóPEZ, José. Consideraciones generales sobre varios puntos históricos, políticos y económicos a favor de la libertad y fomento de los pueblos y noticias particulares de esta clase, relativas al Ferrol y a su comarca. V. Madrid: Imp. de M. Repullés, 1820, p. 134. Agradezco la traducción a la amabilidad de María José Loira Enríquez.

8. Saralegui y Medina, Leandro de. Efemérides ferrolanas. Madrid, 1904, p. 90. Ensenada fue destinado para aplicar en el arsenal de A Graña (Ferrol) «el conocimiento y experiencia con que se halla el referido ministro de lo que se observa en el arsenal de Cádiz, cuyas reglas quiere su majestad se sigan en todo en el Ferrol». Cit. por Gómez URDáÑEz, José Luis. El proyecto reformista de Ensenada. Lleida: Milenio, 1996, p. 66.
} 
Ferrol estaba "en las mejores de las situaciones»". Lo mismo había opinado el jefe de escuadra Cosme Álvarez en 1749 al señalar que "los motivos que me han movido para establecer el Arsenal y Puerto en el Ferrol son tan visibles que hasta los más ygnorantes los indican ${ }^{10}$. Era su respuesta al encargo de Ensenada, formulado en 1747, en donde le indicaba que, puesto que el terreno de A Graña era muy reducido y no era posible formar «un Arsenal capaz de todos los edificios», debía formar otro en la villa de Ferrol «que sea suficiente, aunque sea para 60 navíos de línea y construcción de 4 a un tiempo con todos sus almacenes generales y de desarmo, diques para carenar... y todas las demás ofizinas que son precisas para que pueda llamarse Arsenal completo de Marina ${ }^{11}$. Es obvio que tal determinación estaba en línea con sus planes para el fomento de la Armada, en donde el nuevo arsenal de Ferrol iba a tener un protagonismo muy destacado pues su departamento, frente a los de Cádiz y Cartagena, debía "ser por su situación el más considerable» ${ }^{12}$. Se necesitaba, pues, un arsenal ingente, de gran capacidad, con todas las instalaciones necesarias y bien situado en el centro de una ría que ya gozaba de antiguo de gran fama como segura en lo marítimo e inexpugnable en lo militar ${ }^{13}$, lo que eran valores sin duda adecuados en la guerra defensiva que

9. Cito por la edición francesa. DalRymple, William. Voyage en Espagne et en Portugal dans l'année 1774. Paris, 1783, p. 141. Era escocés, comandante del ejército británico y visitó España en 1774 con la intención de enviar a Inglaterra información estratégica de primera mano. En su obra indicaba que en Ferrol estaba el primer arsenal de la Marina de España y este fue el comentario que publicó en su obra sobre la decisión de Ensenada: «Sus enemigos han pretendido que el motivo de este emplazamiento se debe a que quiso complacer a una amante que poseía bienes considerables en sus alrededores; pero como resulta evidente un juicio aclara que está en las mejores de las situaciones; cualquiera que fuesen los motivos del ministro, los motivos eran lo suficientemente explícitos". Más información sobre su trayectoria por España en GARCía MERCADAL, José. Viajes de extranjeros por España y Portugal. III. Siglo XVIII. Madrid: Aguilar, 1962; RoBERTSON, Ian. Los curiosos impertinentes. Viajeros ingleses por España desde la accesión de Carlos III hasta 1855. Barcelona: Serbal, 1988 y García BlanCO-CiCERÓN, Jacobo. Viajeros angloparlantes por la Galicia de la segunda mitad del siglo XVIII. A Coruña: Fundación Barrié, 2006, pp. 227-241. La edición original en inglés se publicó en Londres en 1777.

10. El comentario lleva la fecha 2 de diciembre de 1749. Archivo General de Simancas: Secretaría de Marina, Arsenales, leg. 376, doc. 9, fol. 1.

11. La carta-orden está firmada en Madrid el 11 de julio de 1747. Museo Naval: Miscelánea, documento n. ${ }^{\circ} 4$, ms. 2139, fol. 7.

12. Así se lo expresaba, en efecto, en su famosa "Representación" sobre el fomento de la Marina dirigida al monarca el 28 de mayo de 1748: «Señor: Sin marina no puede ser respetada la Monarquía española, conservar el dominio de sus vastos estados, ni florecer esta península, centro y corazón de todo... En el reglamento o proyecto adjunto propongo a V. M. de extraordinario, el armamento de seis bajeles para emplearse contra moros y resguardar las costas de España; el de ocho, que son indispensables para que exista, parte en la América y lo demás vaya y venga de ella a Europa; la construcción de seis navíos anuales en Ferrol, Cádiz y Cartagena, y de tres en la Habana, y la fábrica del Arsenal de Ferrol, cuyo departamento debe ser por su situación el más considerable». Cit. por Fernández Duro, Cesáreo. Armada Española. Desde la unión de los reinos de Castilla y de León. VI. Madrid: Museo Naval, 1972, p. 376.

13. Sobre la fama legendaria de la ría de Ferrol como puerto de refugio e inexpugnable puede consultarse Vigo Trasancos, Alfredo y Mera Álvarez, Irene. Ferrol y las defensas del puerto de guerra del rey. La Edad Moderna, 1500-1800. Ferrol: Autoridad Portuaria, 2008, pp. 11 y ss. 
Ensenada buscaba frente a Inglaterra ${ }^{14}$. De ahí que no dudara en aprobar, en 1750, el plan que le había enviado Cosme Álvarez ${ }^{15}$-estimado en casi 25 millones de reales-, aun a sabiendas de que el proyecto establecido por el jefe de escuadra, si bien grande en sus dimensiones, era incompleto, no estaba hecho por un profesional experto -Álvarez era un marino hábil en navegación y logística, pero no un técnico y no contaba en esa fecha con ingeniero alguno a su servicio-, carecía de algunas necesidades apremiantes como los diques de carenar en seco y aun tenía otros notables inconvenientes. Así pues, para Ensenada lo importante en ese momento era tener un proyecto de arsenal aprobado por el rey en la villa de Ferrol para que sirviese de punto de partida; tiempo habría a posteriori para modificarlo en todo lo que fuese necesario.

No deja de resultar curioso, sin embargo, ver como a medida que las arcas del Estado iban llenándose a partir de 1748, tras la paz de Aquisgrán -recuérdese que todavía en 1747 Ensenada se quejaba al rey de los 60 millones de escudos que había costado la guerra que entonces estaba a punto de finalizar ${ }^{16} \mathrm{y}$, en cambio, se felicitaba por los buenos frutos que a las rentas reales de 1750 había proporcionado la situación de paz: 26,5 millones de escudos, sin contar las remesas de Indias que sumaban otros 6 millones ${ }^{17}$, el proyecto para el arsenal de Ferrol fuese adquiriendo cada vez mayor peso y envergadura. En 1747, cuando Ensenada se lo

14. En 1751 tuvo lugar la Representación del marqués de la Ensenada al rey acerca del estado general de la Nación. En ella le indicaba: «Proponer que Vuestra Majestad tenga iguales fuerzas de tierra que la Francia y de mar que la Inglaterra, sería delirio, porque ni la población de España lo permite ni el Erario puede suplir tan formidables gastos; pero proponer que no se aumente el ejército y que no se haga una marina decente sería querer que España continuase subordinada a la Francia por tierra y a la Inglaterra por mar... La armada propuesta es cierto que no puede competir con la Inglaterra, porque esta es casi el doble en navíos y más en fragatas y embarcaciones menores; pero también lo es que la guerra de V M. ha de ser defensiva, y en sus mares y dominios necesitará toda la suya Inglaterra». Vid. "Representación hecha al Sr. D. Fernando el VI por su ministro el marqués de la Ensenada proponiendo medios para el adelantamiento de la monarquía y buen gobierno de ella». Revista del Semanario Erudito, Madrid, 1788, XII, pp. 267-268. Con razón señala GóMEZ URDÁÑEZ, José Luis. El proyecto político del marqués de la Ensenada. Logroño: Universidad de la Rioja, 2008, s. p., que España, en la época de Ensenada, vivió una especie de "paz a la espera" o de "guerra sorda" con Inglaterra que le permitiese rearmarse.

15. El plan de arsenal de Ferrol fue aprobado, en efecto, por R. O. el 14 de enero de 1750. Antes, no obstante, para asegurar que la elección era correcta, Cosme Álvarez inspeccionó las rías de Vigo, Pontevedra y Marín, llegando a hacer planos de ellas que envió al ministro. Pese a ello, Ensenada no dudó en elegir la ensenada ferrolana que era también la opción preferida por el jefe de escuadra. Vid. Bouza Brey, Fermín. "Carta del marqués de la Ensenada desechando la creación del arsenal en Pontevedra y Marín y acordando se haga en Ferrol». Cuadernos de Estudios Gallegos, Santiago, 1961, XVI, pp. 340-341.

16. Cit. por Gómez URdáÑez, José Luis. «Ensenada, hacendista ilustrado». En Durán Boo, Ignacio y CAMARERo Boullón, Concepción (coords.). El Catastro de Ensenada: magna averiguación fiscal para alivio de los vasallos y mejor conocimiento de los reinos: 1749-1756. Madrid: Ministerio de Hacienda, Centro de Publicaciones y Documentación, 2002, p. 84.

17. Ibidem, p. 89. 


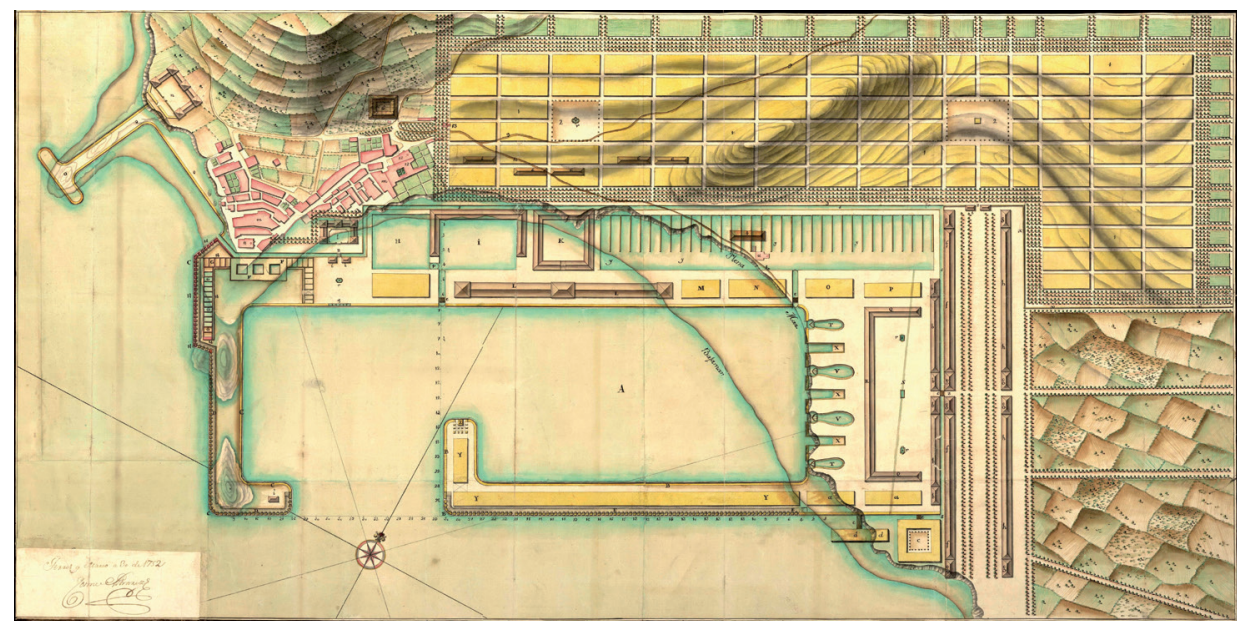

Figura 3. Nuevo proyecto para el arsenal de Ferrol aprobado el 6 de octubre de 1751. Jorge Juan, Cosme Álvarez y Joseph Petit de La Croix. Gobierno de España, Ministerio de Educación, Cultura y Deporte, Archivo General de Simancas, 3, 23.

encarga a Cosme Álvarez, pese a indicarle que debe tener todo lo necesario y una capacidad para 60 navíos de línea, todavía se ve en la obligación de recordarle "que no se gaste más que en lo preciso y no en superfluidades y que las obras que se proyecten no se parezcan en nada a las de ingenieros, que regularmente no hay tesoros para concluirlas ${ }^{18}$. Solo dos años después, en 1749 , ya menciona expresamente que todos los edificios -y eran casi una treintena solo los incluidos en el interior del arsenal y muchos de ellos de grandes dimensiones- se hagan de bóveda para evitar incendios ${ }^{19}$, lo que encarecería notablemente el proyecto; por último, ya en obras el arsenal, vuelve Ensenada a indicarle a Álvarez, en 1751, que por ningún pretexto deje de guardarse regla alguna conducente a la mayor firmeza y hermosura de todas las obras del arsenal aunque sea a costa de 5 o 6 millones más de reales ${ }^{20}$. Es decir, que progresivamente fue adquiriendo su obra magna la grandeza requerida, pues no debía ser solo grandioso el proyecto en su planta y dimensiones, sino magnífico en todos y cada uno de sus edificios. Se justifica, pues, que hasta que cayó Ensenada en 1754 fuese el arsenal ferrolano el que mayores sumas de dinero gastó, tal como señala Merino Navarro, frente a

18. Museo Naval: Miscelánea, documento n. ${ }^{\circ}$ 4, ms. 2139, fol. 7. 11 de julio de 1747.

19. Vid. Rodríguez-Villasante Prieto, Juan Antonio. La obsesión por el orden académico. El arsenal de Ferrol. Madrid: Ministerio de Defensa, 2011, p. 229.

20. Ibidem, p. 237. 
los de Cádiz y Cartagena a los que se asignaron cifras importantes pero siempre mucho más modestas ${ }^{21}$.

\section{El ARSENAl De COSME ÁlVAREz (1747-1750). Un GRAN PROYECTO INCOMPLETO}

Si el encargo de Ensenada tuvo lugar el 11 de julio de 1747, tres años después, el 14 de enero de 1750, el gran proyecto de arsenal formado por Cosme Álvarez era al fin aprobado por el monarca ${ }^{22}$ (Fig. 2). Sin duda era una instalación enorme y vasta en sus dimensiones, con una amplitud desconocida hasta entonces entre los demás puertos militares europeos y, seguramente, el gran arsenal que ambicionaba el ministro, siquiera por su capacidad y por apostar por organizar sus instalaciones con amplias dársenas cerradas por muelles en la línea del arsenal francés de Tolón $^{23}$, que era el más afamado desde el punto de vista portuario ${ }^{24}$. Además estaba ubicado en el lugar más céntrico y resguardado de la ría de Ferrol, en la ensenada en donde se encontraba el puerto pesquero de la villa que estaba protegido hacia el oeste por una serie de islotes rocosos y que se extendía anchuroso hacia el este hasta donde se encontraba el monte de Esteiro, lugar en donde se habían empezado a construir un año antes, en 1749, las gradas de construcción que permitirían a Ensenada iniciar su ansiado plan de construcción naval25.

El nuevo arsenal se disponía justo en el sitio que ya en 1723 había propuesto el ingeniero Francisco Montaigú, años antes de que Patiño tomase la determinación de asentarlo en A Graña ${ }^{26}$. El plan de Álvarez era, no obstante, mucho más espectacular, a tono con las nuevas ideas del ministro, lo que no quiere decir que no tuviese defectos pues ya hemos indicado que fueron muchos los elementos que se modificaron posteriormente. De hecho, pese a su aprobación inicial, era un pensamiento

21. Merino Navarro, José Patricio. La armada española en el siglo XVIII. Madrid: Fundación Universitaria Española, 1981, pp. 171-173.

22. Sobre el proyecto vid. Vigo Trasancos, Alfredo. Arquitectura y urbanismo en el Ferrol del siglo XVIII. Santiago: Colegio Oficial de Arquitectos de Galicia, 1984, pp. 54-58. Sobre su relación con otras obras españolas del momento vid. SAMBricio, Carlos. Territorio y ciudad en la España de la Ilustración, I. Madrid: Ministerio de Obras Públicas y Transportes, 1991, pp. 409 y ss.

23. Sobre el gran arsenal del Mediterráneo francés vid. PETER, Jean. Vauban et Toulon. Histoire de la construction d'un port-arsenal sous Louis XIV. Paris: Economica, 1994. Del mismo autor: Le port et l'arsenal de Toulon sous Louis XIV. Paris: Economica, 1996.

24. No olvidemos que en 1749 Cosme Álvarez se había desplazado a Tolón para ver las obras de los muelles del arsenal. Vid. Rodríguez-Villasante Prieto, Juan Antonio. Op. cit., p. 229.

25. Sobre la construcción del Real Astillero de Esteiro vid. Vigo Trasancos, Alfredo. Op. cit., pp. $115-119$.

26. El ingeniero Francisco Montaigú había realizado, en efecto, en 1723 y en 1732, dos proyectos diferentes para situar el arsenal de Marina en la ensenada de Ferrol como alternativas al que se instaló en la villa de A Graña. Nunca fueron aprobados, no obstante, uno de ellos fue enviado por Ensenada a Cosme Álvarez en 1747 "por si algo aprovechase». Sobre esto vid. ibidem, pp. 51-54 y, como aportación más reciente, Vigo Trasancos, Alfredo y Mera Álvarez, Irene. Op. cit., pp. 64 y ss. 
poco preciso; inconcreto en sus formas demasiado sumisas al recorrido de la costa, muy abierto y expuesto a las aguas, con una mejorable organización interna, tímido a la hora de adentrar sus muelles y espigones sobre el mar y con dos de las tres dársenas previstas casi condenadas a permanecer en seco durante los momentos de la bajamar. Así pues, sus mejores logros eran su diseño alargado adaptado a la ensenada, su relación entre la villa de Ferrol y el naciente astillero de Esteiro, su disposición en "isla" ya que todo el arsenal quedaría separado de tierra firme por un largo foso de agua y, sobre todo, su manera de resolver el muelle oeste, llamado de la Cruz, que casi perfila la forma definitiva que tendría el plan final al disponer un gran malecón-batería que cerraba la dársena principal extendido en el mar en dirección norte sur, con una longitud de casi 500 metros, amplios muelles y explanadas para atraques de navíos y movimiento de las tropas, y todo caracterizado por un remate de martillo, una forma abaluartada al noroeste y con una gran plaza abierta al mar que ya aparece definida por los almacenes de artillería dispuestos en U y presidida por el gran edificio de la Sala de Armas. Tenía previstos, por lo demás, cuadro diques de carenar y cuatro gradas de construcción de navíos, edificios para la cordelería, desarmo, arboladura, teneduría, almacén general, herrerías y un cuartel de presidiarios; asimismo viviendas para el personal y distintas oficinas para la administración, al igual que un gran número de talleres y obradores que se instalaban por lo general mirando a las dársenas. Estas tenían también formatos, diseños y orientaciones diferentes en función de su uso y principal actividad: para maniobra y atraque la principal, para invernada de navíos la segunda más interior y para servir de carenero general la más cerrada de todas ellas. Dos puertas finalmente comunicaban el arsenal con el entorno, disponiéndose una al noroeste en dirección a la villa de Ferrol y la otra al oriente en relación directa con el astillero de Esteiro. Por consiguiente, cabe considerar el proyecto una obra verdaderamente suntuosa que alcanzaría más o menos las 90 hectáreas de superficie, por lo que estaba sobradamente justificado su presupuesto de casi 25 millones de reales que ya hemos señalado.

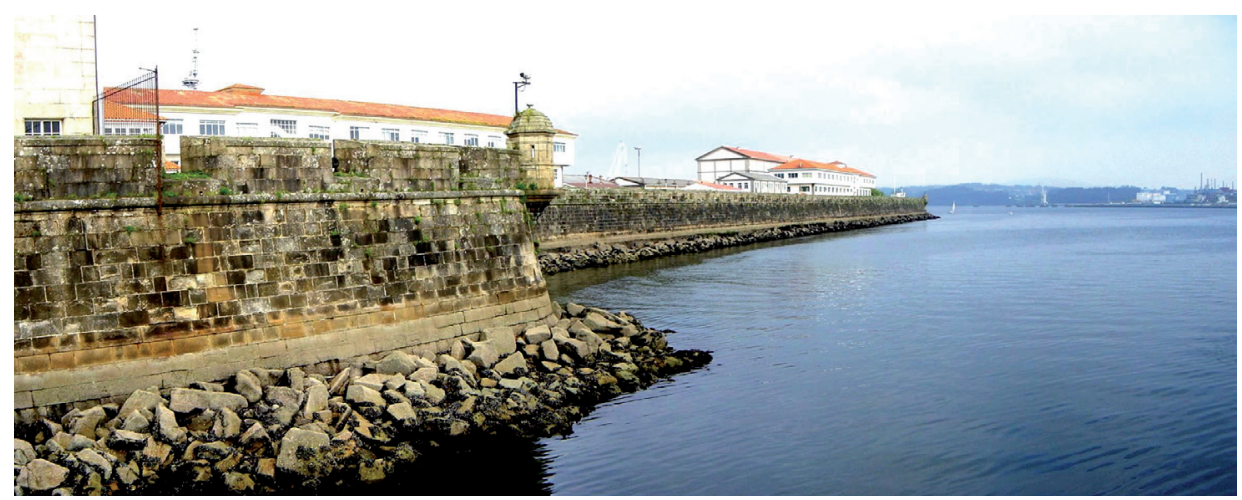

Figura 4. Gran batería defensiva del arsenal de Ferrol. 
Lo curioso del proyecto es que, pese a tan vasta instalación, no prevea el plan de Álvarez, fuera ya del recinto militar, más que dos cuarteles para batallones y brigadas, un hospital naval y un muelle nuevo de carácter civil en la zona de Curuxeiras para cumplir las funciones del antiguo muelle pesquero de Ferrol que el arsenal arrebataba a la villa. No se contempla, pues, recinto fortificado alguno que defendiese las instalaciones militares de un ataque terrestre; tampoco ningún barrio o poblamiento para acoger a los miles de gentes que tendrían que acudir a Ferrol para cubrir las necesidades de la empresa, si bien indicaba Álvarez en carta remitida al ministro que «a la parte de fuera de la Puerta Principal del Arsenal, hay un vello campo dilatado para establecer... vecindario de maestranza porque la villa de Ferrol es mui reducida para acomodar a todos los que precisamente habrán de servir para este arsenal» ${ }^{27}$. Curiosamente olvida también la necesidad de levantar una vivienda específica para servir de residencia al comandante general, cabeza del Departamento que, curiosamente, era el cargo que él mismo desempeñaba desde 1747. Por lo tanto, tiene sentido que el proyecto deba verse como una propuesta mejorable a la espera de que pudiese tenerse información más precisa de las instalaciones que tenían los más afamados arsenales de Europa, no en vano, por estas fechas, Jorge Juan ${ }^{28}$ y Antonio de Ulloa ${ }^{29}$, dos eminentes marinos colaboradores de Ensenada, estaban en misión de espionaje por Inglaterra y diferentes países del norte de Europa precisamente para conocerlos y suministrar al ministro la más cumplida información.

27. Vigo Trasancos, Alfredo. Op. cit., p. 121.

28. Entre noviembre de 1748 y mayo de 1750, Jorge Juan estuvo, en efecto, en Londres en misión de espionaje industrial para informarse del estado y funcionamiento de la Marina, para conocer la organización de sus arsenales y el método de aprendizaje de sus marinos. También para realizar planos de muchos tipos de máquinas y buques de guerra, comprar libros y contratar a expertos en construcción naval. Vid. al respecto Morales HernánDEZ, J. L. "Jorge Juan en Londres». Revista General de Marina, 1973, CLXXXIV, p. 664 y AlBerola RomÁ, Armando y Díe Maculet, Rosario. "Al servicio de la ciencia y del Estado: Jorge Juan Santacilia». En GARCíA HurTAdo, Manuel Reyes (ed.). Ferrol año cero: una ciudad de la ilustración. Ferrol: Embora, 2007, p. 109. También GómEZ UrdáñEZ, José Luis. «El ilustrado Jorge Juan, espía y diplomático». Canelobre: Revista del Instituto Alicantino de Cultura "Juan Gil-Albert», 2006, n. ${ }^{\circ}$ 51, pp. 106-127.

29. Sobre Antonio de Ulloa y Ensenada y su periplo europeo (1749-1752) vid. Helguera QUIJADA, Juan. "Antonio de Ulloa en la época del marqués de la Ensenada. Del espionaje industrial al canal de Castilla (1749-1754)". En Losada, M. y Varela, C. (eds.). Actas del II centenario de don Antonio de Ulloa. Sevilla: Escuela de Estudios Hispanoamericanos, 1995, pp. 197-218. En su viaje por Europa visitó Marsella, Tolón, Rochefort, Dieppe, El Havre, Sette, Port Louis, Nantes, Lorient, La Rochelle, Brest, Sette, Saint-Malo, Paris, Hamburgo, La Haya, Copenhague, Estocolmo, Karlskrona, Berlín, Postdam y Estrasburgo. Entre otros muchos planos había remitido al ministro un plano detallado del arsenal de Tolón que Ensenada el 15 de abril de 1750 pasó a Cosme Álvarez y a Sebastián Feringán, este último responsable del arsenal de Cartagena. Vid. p. 203. 


\section{El arsenal de Jorge Juan (1751). La obra perfecta de EnSENAdA}

Sea como fuere, apenas aprobado el proyecto de Álvarez y ya con el ingeniero militar Joseph Petit de La Croix ${ }^{30}$ a su servicio, pues había llegado a Ferrol a finales del mes de enero de 1750, poco después, en el mes de abril, se iniciaba el acto simbólico del inicio de las obras con la elevación de la tapia que habría de separar el recinto militar de la villa de Ferrol ${ }^{31}$, entonces convertida en el único núcleo de población existente en sus inmediaciones. No se emprendieron obras de mayor empeño aunque sí de organización, tal vez porque Ensenada estaba a la espera de los informes que iba remitiendo Antonio de Ulloa sobre los puertos europeos y porque esperaba la llegada inmediata de Jorge Juan desde Inglaterra para asignarle, tras el preceptivo nombramiento del rey, el cargo de supervisor de las obras de los arsenales que se estaban construyendo y de otras muchas cuestiones de orden naval. Así refiere su secretario personal Miguel Sanz su nombramiento: «A su regreso [de Inglaterra] por mayo de 50 se dignó S.M. encargarle [a Jorge Juan] el arreglo de la construcción de los navíos y demás fábricas de este ramo, igualmente que el proyecto y dirección de los arsenales y sus obras, asociado de los ingenieros y constructores ${ }^{32}$.

Ciertamente no debemos olvidar que, junto a la construcción naval -el 6 de junio de 1750 se colocaba en Esteiro la quilla del navío Asia que junto con el San Fernando y el Castilla fueron los primeros en ser construidos en el astillero ferrolano-, la fábrica del arsenal de Ferrol, junto con el más modesto de Cartagena, eran temas prioritarios para el ministro ${ }^{33}$; y quizá por eso, ansiando resolver cuanto antes la cuestión del proyecto, tomó la determinación de enviar personalmente a Jorge Juan a la capital del Departamento para que de este modo lo pudiese reformar. Llegó a Ferrol en julio de 1751 y todo parece indicar que traía ya dibujada la idea básica que debería aplicarse. Así lo indica Cosme Álvarez en una carta enviada al ministro, si bien le señalaba que había que perfeccionar su forma, adaptarla al terreno y dibujarla con mayor precisión ${ }^{34}$. Todo esto sucedió entre julio de 1751 y el mes de septiembre de ese año, pues sabemos que el 14 de ese mes el plano del nuevo arsenal era enviado a Ensenada. Fue aprobado por el rey el 6 de octubre de este año ${ }^{35}$. Se había realizado bajo la atenta supervisión de Cosme Álvarez, que se encargó de que todo se adaptase al programa general de necesidades; lo había

30. Algunos datos de su actividad pueden encontrarse en CAPEL, Horacio et al. Los ingenieros militares en España. Siglo XVIII. Repertorio biográfico e inventario de su labor científica y espacial. Barcelona: Edicions Universitat de Barcelona, 1983, pp. 371-372.

31. Vigo Trasancos, Alfredo. Op. cit., p. 68.

32. SANZ, Miguel. Breve noticia de la vida del Excmo. Sr. D. Jorge Juan y Santacilia, reducida a los hechos de sus comisiones, obras y virtudes que a instancia de sus apasionados presenta al público su secretario. Madrid: Museo Naval, 1973, s. fol.

33. Vid. nota 12 .

34. Rodríguez-Villasante Prieto, Juan Antonio. Op. cit., p. 236. 10 de agosto de 1751.

35. Vigo Trasancos, Alfredo. Op. cit., p. 58. 
planificado Jorge Juan, su auténtico responsable, y lo había dibujado y adaptado a los pulcros sistemas de representación de la época el ingeniero militar Joseph Petit de La Croix que hizo, en efecto, una obra de diseño de gran calidad. Entre los tres habían sido capaces de dar forma al gran puerto que ambicionaba Ensenada (Fig. 3). Era grande en sus dimensiones -unas 80 hectáreas de superficie-, complejo en las obras hidráulicas que habría que realizar para abrigar su interior del movimiento de las aguas y muy numerosos los edificios que habría que construir, todos de bóveda, mayoritariamente grandes y de piedra y con la "firmeza y hermosura" requeridas. Con razón indicaba Álvarez al ministro que el nuevo arsenal tenía todo lo necesario y que sería admirado en toda Europa, pero que no se concluiría pronto $^{36}$. Curiosamente lo decía casi a la vez que el propio Ensenada, en una de sus características "representaciones", le indicaba al rey que los arsenales de Ferrol y Cartagena serían "perfectos porque se ha copiado lo mejor de Europa y excluido lo malo de ellos ${ }^{37}$.

El nuevo arsenal, impecable en su forma, asentado casi todo él sobre el mar, de una racionalidad absoluta y con unas dimensiones inusuales: 1.400 metros de longitud por 500 metros de ancho, cabe considerarlo una pieza maestra del diseño militar y portuario de la época. Somete todo el conjunto a un proceso de geometrización muy preciso que pasa por definir la forma del arsenal como un rectángulo perfecto en el que apenas se aprecia el breve mordiente necesario para encajar su estructura con la villa de Ferrol que queda, obviamente, fuera de muros. Repite, en cambio, la solución defensiva del sector occidental destinado a la defensa y a parque de artillería del plan de Álvarez -el llamado Arsenal del Parque- presidido por la gran batería (Fig. 4) y la gran construcción de la Sala de Armas. Por el contrario, procede a reordenar todo el resto del conjunto concentrando al norte las dársenas pequeñas para arboladura, embarcaciones menores y enriado de maderas con sus respectivos talleres y almacenes; al este la zona de gradas de construcción y diques de carenar con sus tinglados y servicios -Arsenal de los Diques-; al sur la zona de muelles y espigones con sus martillos muy adentrados en las aguas para cerrar y defender su interior del movimiento del mar y de un ataque marítimo -disponía, en efecto, de una batería a merlones en toda regla que luego fue retirada del plan finalmente construido-, y todo presidido por una enorme dársena rectangular que estaría dividida en dos sectores diferentes: uno menor al oeste para fondeo y maniobras y el segundo al este para atraque, invernada, desarme y reparación de los buques, ambos capaces para 60 navíos de línea; es decir, que bien pudiera considerarse que Jorge Juan había utilizado como unidad de medida compositiva para su plan, siquiera a nivel empírico, las dimensiones básicas de un navío de guerra convencional de tres palos, dos puentes y 70 cañones que,

36. Rodríguez-Villasante Prieto, Juan Antonio. Op. cit., p. 237. 28 de septiembre de 1751.

37. "Representación...». Op. cit., p. 273. 
a mediados del siglo XVIII, alcanzaba más o menos los 50 metros de eslora y 15 metros de manga ${ }^{38}$. Incorpora asimismo el arsenal un foso perimetral como el ya previsto en el proyecto anterior y tres puertas -una más- en directa relación con el entorno. No descuida situar al sur, inmediatos al muelle y dentro del mar, los edificios de herrerías y el presidio, aislados de agua, para evitar la propagación de incendios, las fugas y las sediciones. Por el contrario, es novedosa la solución de crear en el este una plaza de trabajo amplísima mirando hacia el monte de Esteiro, justo delante de la puerta principal y ya traspasado el foso, con almacenes, pabellones para la escuela de pilotos y cuarteles para la maestranza $y$, al noroeste, un noble edificio para servir de residencia al comandante general del departamento que se disponía en frente de la puerta del Parque muy cerca del viejo Ferrol. Por consiguiente, pudiera decirse que se trata de un proyecto de "arsenal completo de Marina" que tanto contempla las exigencias de tipo residencial de los mandos principales y maestranza, como todas las necesidades básicas: defensa de las instalaciones, arme y desarme de los buques, almacén de todo tipo de pertrechos, lugar de construcción y reparación de buques...; y todo bien dispuesto y ordenado para su fácil manejo y con espacios suficientes para facilitar el movimiento de las tropas y de todos los trabajadores. Por lo demás, debía de ser también una instalación aislada y protegida de su entorno, bien comunicada con él, pero a la vez sin perder tampoco la magnificencia debida y la necesidad imperiosa de que los edificios no pudieran ser con facilidad pasto de las llamas. Así pues, hecho y aprobado el proyecto para el que había sido comisionado, Jorge Juan partió para Madrid -bastante maltrecho por un grave accidente que había sufrido en A Graña- donde sabemos que informó al marqués de la Ensenada de las necesidades de personal que necesitarían todas las obras ferrolanas. En 1753 su secretario Miguel Sanz indicaba que trabajaban en Ferrol 15.000 hombres ${ }^{39}$.

En todo caso, entre 1751 y 1754 en que tuvo lugar la caída de Ensenada, las obras ferrolanas avanzaron a un ritmo bastante apurado sobre todo en el sector occidental del arsenal que era el más expuesto y el de más compleja construcción -entre mayo de 1750 y agosto de 1753 se habían consumido en las obras 18.069.365 reales de vellón cuando apenas se había ejecutado una sexta parte del proyecto aprobado- ${ }^{40}$, aunque también se hicieron algunas infraestructuras del muelle norte, del muelle sur y la excavación básica para iniciar uno de los diques de carenar en seco que se disponían en el sector oriental del proyecto. En este tiempo se sucedieron cuatro directores ${ }^{41}$ : Cosme Álvarez, que era marino del

38. http://www.todoababor.es/vida_barcos/nav.htm. (fecha de consulta: 02/06/2015).

39. "Quando a fines del propio año 53, que murió en Ferrol el comandante general D. Cosme Álvarez, a cuyo zelo y suficiencia se había fiado con especial encargo el auxilio y cuidado de aquellas vastas obras y construcción, en que a la sazón trabajaban 15000 hombres». SANZ, Miguel. Op. cit., s. fol.

40. Vid. Rodríguez-Villasante Prieto, Juan Antonio. Op. cit., p. 241.

41. Vigo Trasancos, Alfredo. Op. cit., pp. 72-74. 


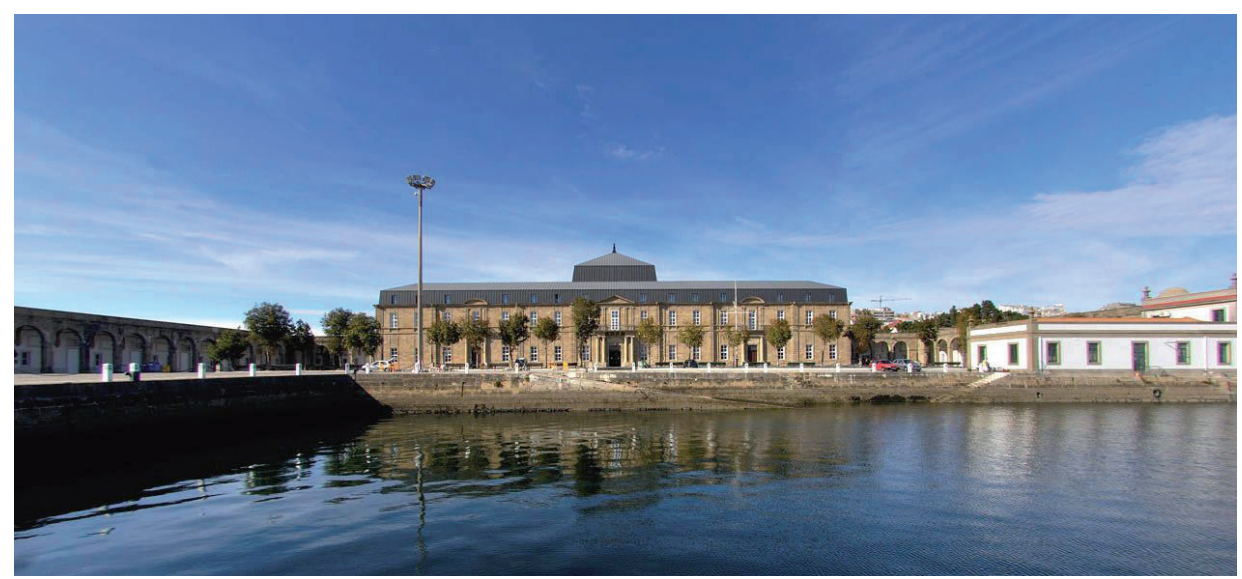

Figura 5. Vista general de la plaza y Sala de Armas del arsenal de Ferrol tras la restauración del arquitecto Iago Seara. Fotografía de Manuel González Vicente.

cuerpo general de la Armada -hasta marzo de 1752-; Miguel Marín, ingeniero del ejército -hasta marzo de 1753-; Jorge Juan, marino de guerra y científico -entre octubre de 1753 y marzo de 1754-, y Francisco Llobet, que era también ingeniero militar -a partir de marzo de 1754 y hasta junio de 1762-. Igualmente trabajó como técnico muy destacado el ingeniero Joseph Petit de La Croix, que ya hemos mencionado, al que hay que atribuir seguramente los primeros diseños que se fueron elaborando para los distintos edificios, entre los que destacan los almacenes de artillería porticados y la Sala de Armas que ya empezó a configurarse con un diseño grandioso de tipo francés que superaba con creces lo que hasta entonces se había visto en un arsenal ${ }^{42}$ (Fig. 5). Es la viva imagen de la magnificencia que Ensenada ambicionaba para el proyecto, pues sus grandes proporciones, su noble construcción en sillar, la altura del edificio y su curioso volumen cubierto con una llamativa mansarda estaban llamados a ser el referente arquitectónico del arsenal y en definitiva un signo de fuerte evocación simbólica que se asocia inequívocamente a la imagen del poder y con la idea de fuerza que emana de la monarquía -RERUM, DEUS, TENAX, VIGOR fue la inscripción que se puso en

42. Sobre ella véase ibidem, pp. 80-91. En relación con la formación académica y arquitectónica recibida por los ingenieros militares en la España del siglo XVIII vid. CAPEL, Horacio; SÁnCHEZ, Joan Eugeni y MONCADA, Omar. De Palas a Minerva. La formación científica y la estructura institucional de los ingenieros militares en el siglo XVIII. Barcelona: Serbal, 1988 y MuÑoz Corbalán, Juan Miguel (coord.). La Academia de Matemáticas de Barcelona. El legado de los ingenieros militares. Madrid: Ministerio de Defensa, 2004. También CÁmara, Alicia (coord.). Los ingenieros militares de la monarquía bispánica en los siglos XVII y XVIII. Madrid: Ministerio de Defensa, 2005. 
su puerta- ${ }^{43}$; más aún cuando, en el año 1754 , Juan y Llobet le incorporaron a la cubierta una cúpula quebrantada que domina centrada sobre su cumbre y, en el interior, una noble escalera imperial de ceremonia con otras dos de servicio en su parte posterior que sorprenden por su solemnidad (Figs. 6 y 7) en un edificio de sus características: un gran almacén de armas. Se explica, seguramente, por su carácter de símbolo de majestad, porque era el primer edificio que se veía cuando los barcos se adentraban en el interior la dársena y porque no es imposible que estuviese prevista para ser usada ocasionalmente en algún ceremonial oficial -seguramente en la planta alta que mira al balcón principal y que podía acondicionarse para la ocasión- cuando las escuadras extranjeras visitaban el puerto y era necesario cumplimentar a sus respectivas autoridades. Sea como fuere, prueba como pocas construcciones hispanas la fascinación que la arquitectura militar de la época sintió por los modelos foráneos de tipo francés, no en vano se aprecian en el edificio muchos influjos de la arquitectura gala aprendidos en tratados como los de Augustín-Charles d'Aviler, Charles Etienne Briseux o el ingeniero Bernard Forest de Belidor, todos muy utilizados en la época ${ }^{44}$.

Entre los técnicos que trabajaron en el arsenal ferrolano en la época de Ensenada debe llamarse la atención sobre Julián Sánchez Bort ${ }^{45}$ que llegó a la ciudad departamental en enero de 1754, el mismo año de la caída en desgracia del ministro. Trabajó desde entonces a las órdenes de Llobet, con el que no tuvo nunca buenas relaciones. No obstante, más allá de este tipo de cuestiones, nos interesa destacar que era hombre de confianza de Ensenada, también un fiel colaborador de Jorge Juan, un ingeniero adscrito a la Marina y, además, un técnico muy cualificado pues era experto en ingeniería hidráulica, un gran conocedor de las

43. Mera Álvarez, Irene. "Portada principal de la sala de armas del arsenal de Ferrol». En VigO Trasancos, Alfredo (dir.). Galicia y el siglo XVIII. Planos y dibujos de arquitectura y urbanismo (17011800). A Coruña: Fundación Barrié, 2011, p'. 271, plano 682. Hoy desaparecida, la inscripción la menciona colocada sobre la puerta principal MONTERo ARÓSTEGUI, José. Historia y descripción de la ciudad $y$ departamento naval del Ferrol. Madrid: Imprenta de Beltrán y Viñas, 1859, p. 476.

44. Vigo Trasancos, Alfredo. "Los tratados de arquitectura de Belidor, Briseux y D'Aviler en la formación de los ingenieros militares: el ejemplo de la Sala de Armas del arsenal de Ferrol». En Jubilatio. Homenaje de la Facultad de Geografía e Historia a los profesores D. Manuel Lucas Álvarez y D. Ángel Rodríguez González, t. II. Santiago: Servicio de Publicaciones e Intercambio científico de la Universidad de Santiago de Compostela, 1987, pp. 669-680. Sobre el ingeniero Francisco Llobet vid. GALCERÁN, Margarita. "Francisco Llovet, ingeniero director en el Principado de Cataluña». En DE LizAUR Y DE UTRILla, Antonio (coord.). La Ilustración en Cataluña: la obra de los ingenieros militares. Madrid: Ministerio de Defensa, 2010, pp. 192-210.

45. Como obras de referencia sobre este ingeniero hidráulico pueden consultarse Vigo TrASANCOS, Alfredo. "El arquitecto-ingeniero Julián Sánchez Bort. Perfil biográfico y obra en Galicia». Cuadernos de Estudios Gallegos, 1984-85, XXXV, pp. 501-525; RodríGuEZ-VILlaSANTE PrieTO, Juan Antonio. Tecnología y arte de la ilustración. La arquitectura e ingeniería de Sánchez Bort en la obra pública, la industria y los arsenales de Marina. Pontedeume: Asamblea Amistosa Literaria, 1988 y Vigo TrasANCOS, Alfredo. «Julián Sánchez Bort». En Artistas Galegos. Arquitectos (da Ilustración ó Eclecticismo). Vigo: Nova Galicia Edicións, 2003, pp. 62-83. 


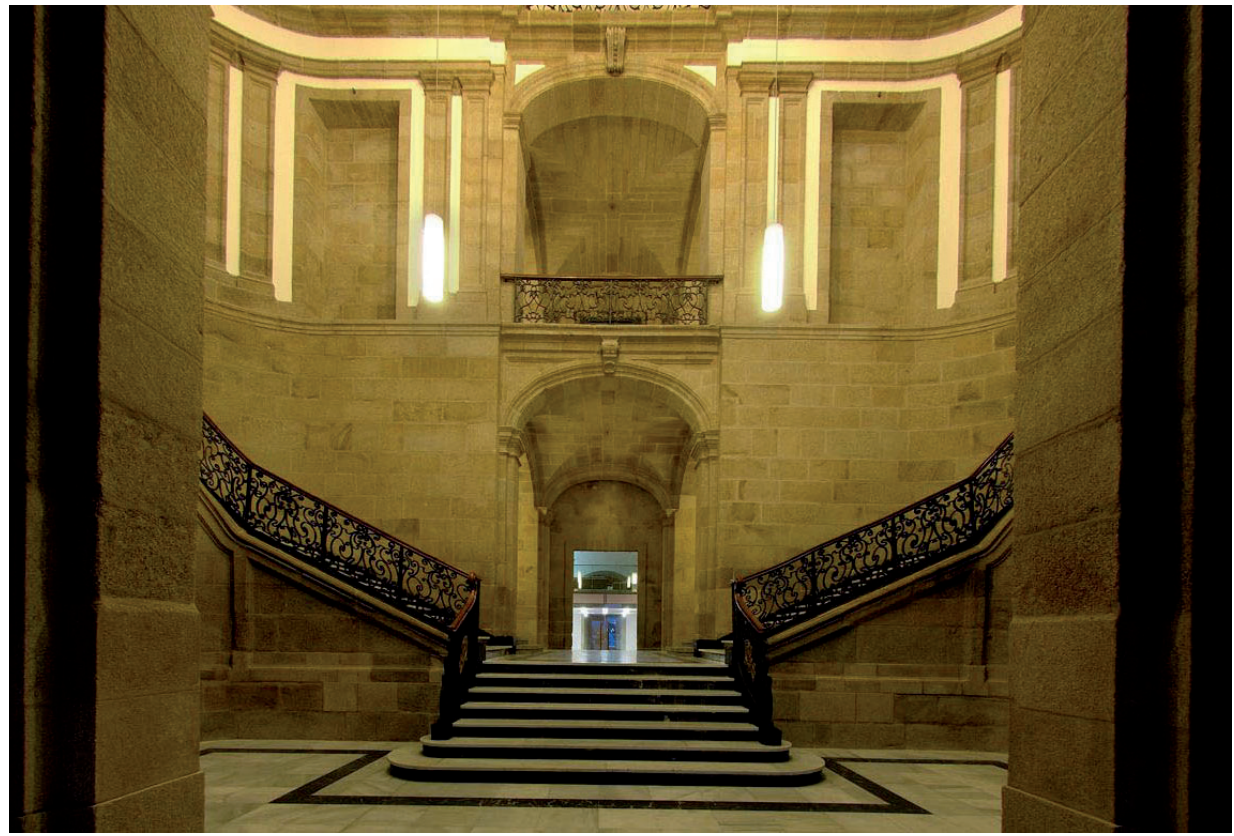

Figura 6. Vista de la escalera principal de la Sala de Armas del arsenal de Ferrol tras la restauración del arquitecto Iago Seara. Fotografía de Manuel González Vicente.

grandes obras portuarias europeas y un alumno de la Academia de Bellas Artes de San Fernando de Madrid que garantizaba una adecuada formación arquitectóni$\mathrm{ca}^{46}$; por eso que debamos ver en la llegada del ingeniero-arquitecto una primera intención del tándem Ensenada-Jorge Juan de ir relanzando paulatinamente a un ingeniero de la Armada para que fuese sustituyendo en los puestos decisivos del arsenal a los ingenieros del Ejército que habían llevado hasta entonces el peso de las obras ${ }^{47}$. Tuvo todavía que esperar varios años para dirigir las obras, pues no se produjo la sustitución de Llobet hasta el mes de junio de 1762, cuando Sánchez Bort tomó su relevo ya en pleno reinado de Carlos III.

46. En relación con lo complejo del pensamiento arquitectónico de la España ilustrada y el papel de la Academia, como obra de referencia puede consultarse SAMBricio, Carlos. La arquitectura española de la Ilustración. Madrid: Consejo Superior de los Colegios de Arquitectos de España, 1986.

47. Vid. al respecto Vigo Trasancos, Alfredo. "Los ingenieros de Marina y el Reino de Galicia (1754-1800)». En GarCía HuRTAdo, Manuel Reyes (ed.). La armada española en el siglo XVIII. Ciencia, hombres y barcos. Madrid: Ś1lex, 2012, pp. 66 y ss. 


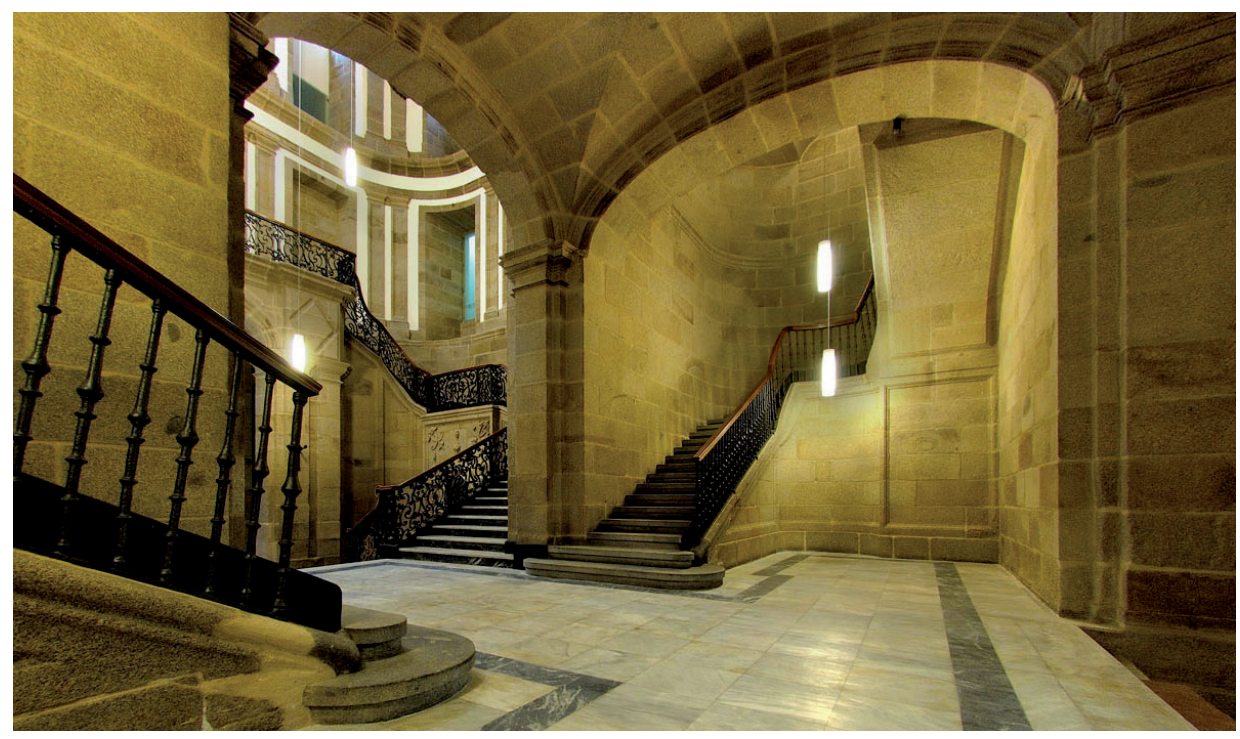

Figura 7. Vista del conjunto de escaleras de la Sala de Armas del arsenal de Ferrol tras la restauración del arquitecto Iago Seara. Fotografía de Manuel González Vicente.

\section{LA FORMACIÓN DE LA CIUDAD-ARSENAL. UN SUEÑO DE ORDEN}

Las obras del nuevo arsenal, iniciadas como hemos dicho a mediados de 1750, y la instalación un año antes del astillero en Esteiro con 12 gradas de construcción hicieron que llegasen a la villa diferentes contingentes de tropas para el control y la defensa y miles de personas para atender las muchas necesidades administrativas y laborales que se contemplaban: canteros, carpinteros de ribera, funcionarios, vivanderos y todo tipo de maestranza. 15.000 personas nada menos cuantifica para 1753 el bien informado Miguel Sanz, secretario personal de Jorge Juan. Quiere esto decir que la villa de Ferrol, que apenas alcanzaba en esa data una población de 1.500 habitantes $^{48}$, se vio totalmente desbordada, incapaz de acoger a tanta nueva concurrencia y tuvieron que ser las autoridades militares -primero Cosme Álvarez hasta su muerte en 1753 y luego sus sucesores- las que organizaron provisionalmente todas las necesidades más apremiantes que se plantearon. De hecho, justo a las puertas del astillero de Esteiro, se formó una gran plaza rectangular llamada «el Cuadro» alrededor de la cual se levantaron largos pabellones de pobre fábrica para acoger a los empleados del Departamento, la contaduría y la intendencia y asimismo, aunque en una posición más secundaria, largos barracones para alojar a los muchos "viscainos» y obreros que

48. Vigo Trasancos, Alfredo. Arquitectura y urbanismo... Op. cit., p. 136. 
habían sido desplazados para trabajar en Ferrol $^{49}$. Por la misma razón, en esta zona empezó a levantarse, a partir más o menos de 1750-51, un poblado de barracas para vivanderos, familias y primeros moradores vinculados a la realidad obrera que, alineadas y formando estrechas calles rectilíneas, a la manera de un campamento militar, fueron dando paso al «lugar nuevo» que, con el tiempo, daría forma al barrio de Esteiro, en realidad un auténtico poblado provisional de emergencia ${ }^{50}$. Por la zona donde se encontraba la capilla de la Magdalena también se levantó un hospital provisional, unas herrerías de obra y unos hornos de cierta amplitud para hacer ladrillos y tejas muy necesarios para las obras. Por lo tanto, junto con el taller para canteros y otro almacén para disponer los utensilios de trabajo que se instalaron en la villa de Ferrol, los almacenes de provisión y los cinco cuarteles para las tropas que se levantaron en la zona de San Roque y en las huertas inmediatas - en ellos se alojaron las brigadas y los batallones de Marina y los llamados regimientos de Hibernia, Irlanda y Ultonia-, solo faltaba la apertura de un camino nuevo que comunicase con facilidad la villa de Ferrol y el astillero de Esteiro y facilitara el trasiego de las personas. Todo se hizo en los años iniciales por la vía de emergencia ${ }^{51}$.

El proyecto de arsenal de Jorge Juan daba, sin embargo, cumplida respuesta a todas las necesidades (Figs. 3 y 8), hasta tal punto que la pequeña villa de Ferrol, ya destinada a partir de entonces a llamarse Ferrol Viejo, quedó convertida en un núcleo extremo y marginal por completo asociado a antiguos modos de vida y, a su vez, en un ejemplo de praxis urbana nada modélico. Por el contrario, todo lo demás que contemplaba el proyecto recibió una estricta ordenación que fue ejecutada sobre el papel de manera impecable por el ingeniero militar Joseph Petit de La Croix. Así, los dos cuarteles oficiales previstos para las brigadas y los batallones de Marina $^{52}$ se dispusieron en lugares dominantes, aislados de los núcleos de población, con vistas magníficas sobre el entorno y con unas plantas de tipo moderno y monumental, quizá para de este modo mantener su independencia, dar imagen del poder y recordar a todos los moradores su dominio sobre la villa; asimismo, el edificio de la Comandancia General se instaló justo enfrente de la puerta occidental del arsenal, buscando la conexión inmediata con las instalaciones militares, si bien en un lugar llano ganado al mar inmediato a la villa de Ferrol que quedaría muy cercano a la plaza Vieja hoy llamada del marqués de San Saturnino ${ }^{53}$. No falta

49. Ibidem, pp. 128-132.

50. Ibidem., pp. 121-128.

51. Toda esta información se indica en un plano de la villa y arsenal de Ferrol realizado por Francisco Llobet el 30 de septiembre de 1754. Vid. GómEz IPARRAGUIRRE, Jorge. "Dársena y muelles del arsenal de Ferrol con estado de las obras en septiembre de 1754». En Vigo Trasancos, Alfredo (dir.). Op. cit., p. 250, plano 597.

52. Vigo Trasancos, Alfredo. Arquitectura y urbanismo... Op. cit., pp. 174-186.

53. Al respecto vid. Vigo Trasancos, Alfredo. "La "Casa del Rey" en la que vive el comandante general del Departamento Marítimo de Ferrol. Símbolo de poder y nudo urbano de la nueva ciudad dieciochesca (1751-1768)». Minius, 2011, n. ${ }^{\circ}$ 19, pp. 155-177. 
tampoco la proyección de un puerto civil y pesquero para el servicio de la villa, justo en la zona costera de Curuxeiras, donde dispone el proyecto la construcción de un largo malecón con su martillo terminal en T que formaría un muelle y una dársena importantes, sobre todo teniendo en cuenta la escasa infraestructura portuaria que solían tener los puertos gallegos incluido el de A Coruña que era, sin duda, el más activo y principal de todo el reino de Galicia ${ }^{54}$. También atiende el plan de Juan a la necesidad de establecer una perfecta separación entre la zona civil y la zona militar separando ambos sectores por un larguísimo muro -aproximadamente de 3.900 metros de longitud- que recorrería en sentido O-E todo el conjunto de las reales obras, desde Curuxeiras, hasta la ensenada de Caranza, en donde se dispuso, justo enfrente del astillero de Esteiro, una amplia zona para establecer el dique de maderas empleadas en la construcción naval. Por lo tanto, en el Ferrol que miraba al mar se estableció una secuencia notable de muelles e instalaciones militares que cabe considerar magnífica y perfecta en su funcionalidad: primero, con el puerto civil de Curuxeiras al oeste mirando a la boca de la ría y a continuación, ya en dirección a oriente, el gran arsenal, luego la ribera de Fontelonga en donde se instalaba un pequeño muelle para uso de Esteiro, más allá el real astillero con sus doce gradas de construcción dispuestas en abanico y, al fondo, en el recodo abrigado de Caranza, el gran dique de maderas, todo encerrado dentro de los muros ya mencionados que se reforzaban en el entorno terrestre del arsenal con un larguísimo foso de agua.

El plan de Juan no olvida obviamente otra necesidad imperiosa: la formación de una "ciudad nuevamente proyectada" tal como se indica en la leyenda ${ }^{55}$. Es la imagen opuesta a la vieja villa medieval de Ferrol, amplia, larga, regular, perfectamente ortogonal en su trazado, con su parcelario y manzanas muy homogéneas, bien acomodada al declive del terreno y en forma de amplio rectángulo con un remate en martillo que con su disposición en L acostada se adapta perfecta al formato del arsenal. Claramente revela en su traza la larga experiencia de las ciudades nuevas reticulares y del urbanismo militar propenso a adoptar por su eficiencia este tipo de planteamientos simples y sistemáticos. Estaba prevista para un blanco de población estimado entre 20.000 y 30.000 habitantes y con dos plazas porticadas en sus extremos, lo que le otorga al conjunto un sentido claramente bipolar, muy coherente con el formato alargado de todo el diseño urbano. Por lo demás, su misma bipolaridad y el sector poblacional dispuesto en forma de martillo al este pueden estar justificados por la doble servidumbre de la ciudad nueva al arsenal y al astillero de Esteiro, sobre todo si tenemos en cuenta que el poblado de barracas que se había empezado a formar en sus inmediaciones era un asentamiento de emergencia que estaba previsto derribar una vez la nueva ciu-

54. Sobre la ciudad de A Coruña en este siglo puede consultarse Vigo Trasancos, Alfredo. $A$ Coruña y el siglo de las luces. La construcción de una ciudad de comercio (1700-1808). Santiago: Servicio de Publicaciones de las Universidades de Santiago de Compostela y A Coruña, 2007.

55. Vid. Vigo Trasancos, Alfredo. Arquitectura y urbanismo... Op. cit., pp. 142-143. 


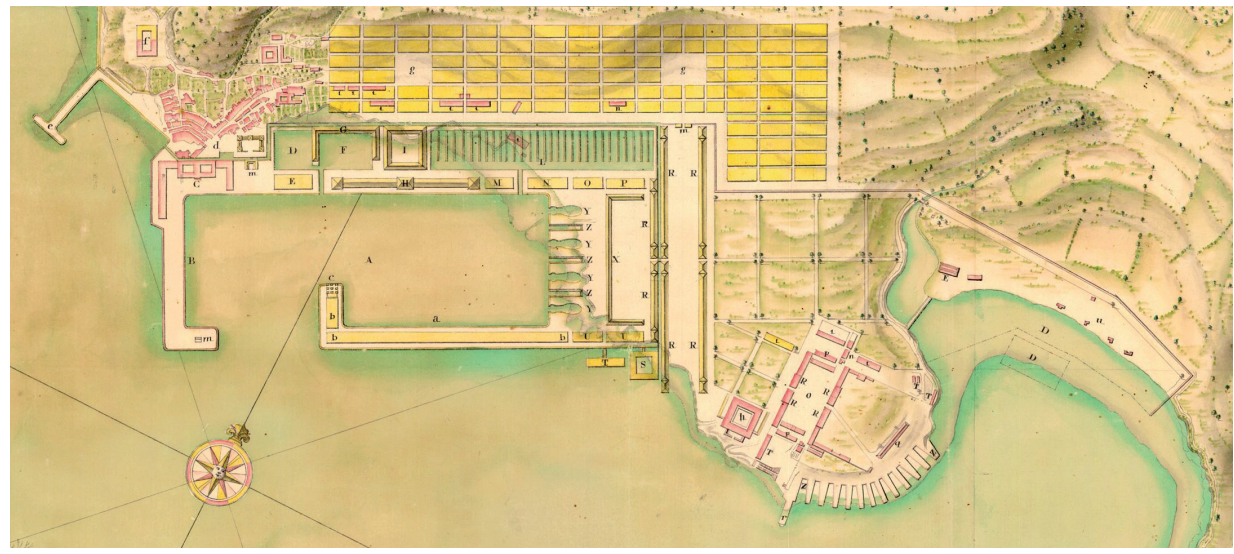

Figura 8. Plano del arsenal y la ciudad de Ferrol con el astillero de Esteiro y la ensenada de Caranza. C. 1751-1754. Archivo Cartográfico y de Estudios Geográficos del Centro Geográfico del Ejército, armario E, tabla 4. ${ }^{\mathrm{a}}$, carpeta 4. ${ }^{\mathrm{a}}, \mathrm{n}^{\circ}{ }^{\circ} 113$.

dad empezase a levantarse. Así pues, cabe suponer que el sector más oriental de la nueva población con su martillo y plaza próxima estaría pensado para acoger a la población obrera distribuida entonces por Esteiro y el sector más occidental, en cambio, para el resto de los nuevos moradores que así tendrían mayor proximidad a las instalaciones militares del arsenal, este también con su plaza correspondien$t^{56}$. Y todo perfectamente aislado del entorno por una alameda perimetral que, a la manera de una gran barrera de verdor, circunvalaría la ciudad nueva ensimismándola del mismo modo que el foso y la muralla las instalaciones militares.

Llama la atención, no obstante, que no se prevea ningún recinto fortificado, ninguna arquitectura monumental civil o religiosa, ni tampoco ninguna jerarquía viaria, lo que parece indicar que se quiso proyectar simplemente una ciudad dormitorio de servicio, en todo muy igualitaria y homogénea, difícil de atacar desde tierra. Sea como fuere, todo lo analizado fue el sueño de orden pensado por Jorge Juan para dar cumplida respuesta a los deseos de Ensenada. Un puerto de guerra magnífico, perfecto en sus formas, amplio en sus dimensiones, suntuoso en su arquitectura, con una solución idónea para cada necesidad, con todo ordenado conforme a la autoridad suprema de la razón, con la tecnología más actual y con dársenas muy espaciosas. En definitiva, un puerto militar como el mundo no había

56. Ibidem, pp. 121-169. También Clemente Cubillas, Enrique. Desarrollo urbano y crisis social en Ferrol. Santiago de Compostela: Ediciones de la Universidad de Salamanca, 1984 y ClEMENTE CuBILLAS, Enrique. "Ferrol ayer y hoy: de la urbanización inicial del siglo XVIII a la actual ciudad del XXI". En Agulló Leal, Fernando Luis (coord.). Cátedra Jorge Juan. Ciclo de Conferencias, curso 2011-2012. Ferrol, 2013. 
conocido, ni siquiera en el famoso puerto de Trajano en Ostia, pasmo de la Antigüedad, que sin duda Juan y Ensenada quisieron superar con creces ${ }^{57}$. Con razón, la placa de plomo que se colocó finalmente en la puerta principal del arsenal proclama al mundo que era «el monumento más notable del orbe» y «una obra de arte suprema ${ }^{58}$. No llegó a construirse en su totalidad conforme al proyecto de 1751; la caída de Ensenada primero, luego la ralentización de las obras y los menores recursos y las prisas por culminarlo que llegaron más tarde hicieron que, en 1761, ya en el reinado de Carlos III, el arsenal junto con sus obras complementarias sufriesen importantes reducciones. Con todo, sigue siendo el actual arsenal carolino que ha llegado hasta nosotros una obra extraordinaria que debe ser considerada, entre las de su género, entre las más sobresalientes de la Europa de su tiempo y acaso, como ya se ha dicho, "la obra sublime... de un gran rey».

\section{BIBLIOGRAFÍA}

ABAD LeÓn, Felipe. El marqués de la Ensenada. Logroño: Diputación Provincial, 1981, pp. 49-50.

Alberola Romá, Armando y Díe Maculet, Rosario. "Al servicio de la ciencia y del Estado: Jorge Juan Santacilia». En García HurTado, Manuel Reyes (ed.). Ferrol año cero: una ciudad de la ilustración. Ferrol: Embora, 2007, pp. 101-130.

ALONSO LóPEZ, José. Consideraciones generales sobre varios puntos históricos, politicos y económicos a favor de la libertad y fomento de los pueblos y noticias particulares de esta clase, relativas al Ferrol y a su comarca. V. Madrid: Imprenta de M. Repullés, 1820.

Bonet CORREA, Antonio y Blasco Esquivias, Beatriz (comisarios). Un reinado bajo el signo de la paz. Fernando VI y Bárbara de Braganza 1746-1759. Madrid: Real Academia de Bellas Artes de San Fernando, 2003.

57. Vigo Trasancos, Alfredo. "Marte y Mercurio unidos por Hércules. El sueño ilustrado de un gran puerto hispano-indiano en el Golfo de los Ártabros (1720-1788)». En Actas del XVIII Congreso del C.E.H.A. Mirando a Clío. El arte español como espejo de su historia, III. Santiago, 2012, pp. 1730-1751.

58. Esta es la inscripción completa que aparece sobre la puerta: «Maximum supreme artis quid videre volenti. Praecipuum hic orbis illi sistitur opus; in quo firmiter perlustrantes maria cuncta, naves, procinctus clases, atque omnia videt. ¿O felix Hispania. Admodumque felix: Te fauste gubernat, regit, tibique sapienter imperat Carolus III, rex inclitus, piissimus, augustus: quem totus non capit orbis». La traducción castellana es la siguiente:

Para el que quiera contemplar una maravilla de arte supremo

aquí se presenta el monumento más notable del orbe, en donde

puede admirar las poderosas escuadras dispuestas a surcar todos los mares,

¡Oh España feliz y dichosa en grado sumo!

Te gobierna y rige con esplendor y ejerce su imperio con sabiduría

Carlos III,

El Rey ínclito, piadosísimo, augusto, para el cual el mundo es pequeño, Año de 1783.

Cit. por GAYOSO, Justo. "Ferrol, Departamento marítimo del Norte». En Almanaque de Ferrol para el año 1907. Ferrol, 1906, p. 56. 
"ESTA OBRA SUBLIME ES LA SEÑAL DE UN GRAN REY»: LA CIUDAD-ARSENAL DE FERROL...

BouZA BREY, Fermín. "Carta del marqués de la Ensenada desechando la creación del arsenal en Pontevedra y Marín y acordando se haga en Ferrol». Cuadernos de Estudios Gallegos. Santiago, 1961, XVI, pp. 340-341.

CÁmara, Alicia (coord.). Los ingenieros militares de la monarquía hispánica en los siglos XVII y XVIII. Madrid: Ministerio de Defensa, 2005.

CAPEL, Horacio et al. Los ingenieros militares en España. Siglo XVIII. Repertorio biográfico e inventario de su labor científica y espacial. Barcelona: Publicacions de la Universitat de Barcelona, 1983.

CAPEl, Horacio; SÁnchez, Joan Eugeni y Moncada, Omar. De Palas a Minerva. La formación científica y la estructura institucional de los ingenieros militares en el siglo XVIII. Barcelona: Serbal, 1988.

Clemente Cubillas, Enrique. Desarrollo urbano y crisis social en Ferrol. Santiago de Compostela: Ediciones de la Universidad de Salamanca, 1984.

ClEmEnTE Cubillas, Enrique. «Ferrol ayer y hoy: de la urbanización inicial del siglo XVIII a la actual ciudad del XXI». En Agulló LEAL, Fernando Luis (coord.). Cátedra Jorge Juan. Ciclo de Conferencias, curso 2011-2012. Ferrol, 2013.

DALRYMPLE, William. Voyage en Espagne et en Portugal dans l'année 1774. Paris, 1783.

Durán Boo, Ignacio y CAMARERo Boullón, Concepción (coords.). El Catastro de Ensenada: magna averiguación fiscal para alivio de los vasallos y mejor conocimiento de los reinos: 1749-1756. Madrid: Ministerio de Hacienda, Centro de Publicaciones y Documentación, 2002.

FERnÁNDEZ DuRo, Cesáreo. Armada Española. Desde la unión de los reinos de Castilla y de León. VI. Madrid: Museo Naval, 1972.

GALCERÁN, Margarita. «Francisco Llovet, ingeniero director en el Principado de Cataluña». En De Lizaur y De Utrilla, Antonio (coord.). La Ilustración en Cataluña: la obra de los ingenieros militares. Madrid: Ministerio de Defensa, 2010, pp. 192-210.

GARCía BlANCO-CicERÓN, Jacobo. Viajeros angloparlantes por la Galicia de la segunda mitad del siglo XVIII. A Coruña: Fundación Barrié, 2006.

García HurTado, Manuel Reyes (ed.). Ferrol año cero: una ciudad de la ilustración. Ferrol: Embora, 2007.

García Hurtado, Manuel Reyes (ed.). La armada española en el siglo XVIII. Ciencia, hombres y barcos. Madrid: Sílex, 2012.

García Mercadal, José. Viajes de extranjeros por España y Portugal. III. Siglo XVIII. Madrid, Aguilar, 1962.

Gayoso, Justo. «Ferrol, Departamento marítimo del Norte». En Almanaque de Ferrol para el año 1907. Ferrol, 1906.

GÓmeZ IPARRAGUiRRe, Jorge. "Dársena y muelles del arsenal de Ferrol con estado de las obras en septiembre de 1754». En Vigo Trasancos, Alfredo (dir.). Galicia y el siglo XVIII. Planos y dibujos de arquitectura y urbanismo (1701-1800). A Coruña: Fundación Barrié, 2011, p. 250, plano 597.

GómEZ URDÁÑEZ, José Luis. El proyecto reformista de Ensenada. Lleida: Milenio, 1996.

Gómez Urdáñez, José Luis. Fernando VI. Madrid: Arlanza ediciones, 2001.

Gómez UrdáÑEz, José Luis. Carvajal-Ensenada: Un binomio político. Córdoba: Universidad de Córdoba, 2002.

GÓmez URdáÑEZ, José Luis. "Ensenada, hacendista ilustrado». En DuRán BoO, Ignacio y CAMARERO Boullón, Concepción (coords.). El Catastro de Ensenada: magna averiguación fiscal para alivio de los vasallos y mejor conocimiento de los reinos: 1749-1756. 
Madrid: Ministerio de Hacienda, Centro de Publicaciones y Documentación, 2002, pp. 83-99.

GÓMEZ URDÁÑ̃z, José Luis. «El ilustrado Jorge Juan, espía y diplomático». Canelobre: Revista del Instituto alicantino de cultura "Juan Gil-Albert", 2006, n. ${ }^{\circ}$ 51, pp. 106-127.

GÓMEZ URDÁÑEz, José Luis. El proyecto político del marqués de la Ensenada. Logroño: Universidad de la Rioja, 2008.

Helguera Quijada, Juan. "Antonio de Ulloa en la época del marqués de la Ensenada. Del espionaje industrial al canal de Castilla (1749-1754)». En LOSADA, M. y VARELA, C. (eds.). Actas del II centenario de don Antonio de Ulloa. Sevilla: Escuela de Estudios Hispanoamericanos, 1995, pp. 197-218.

Losada, M. y Varela, C. (eds.). Actas del II centenario de don Antonio de Ulloa. Sevilla: Escuela de Estudios Hispanoamericanos, 1995.

Mera Álvarez, Irene. «Portada principal de la sala de armas del arsenal de Ferrol». En Vigo Trasancos, Alfredo (dir.). Galicia y el siglo XVIII. Planos y dibujos de arquitectura y urbanismo (1701-1800). A Coruña: Fundación Barrié, 2011, p. 271, plano 682.

Merino Navarro, José Patricio. La armada española en el siglo XVIII. Madrid: Fundación Universitaria Española, 1981.

Montero Aróstegui, José. Historia y descripción de la ciudad y departamento naval del Ferrol. Madrid: Imprenta de Beltrán y Viñas, 1859.

Morales HernándeZ, J. L. "Jorge Juan en Londres". Revista General de Marina, 1973, CLXXXIV.

MuÑoz Corbalán, Juan Miguel (coord.). La Academia de Matemáticas de Barcelona. El legado de los ingenieros militares. Madrid: Ministerio de Defensa, 2004.

OZANAM, Didier. "El marqués de la Ensenada». En Un reinado bajo el signo de la paz. Fernando VI y Bárbara de Braganza 1746-1759. Madrid: Real Academia de Bellas Artes de San Fernando, 2003, pp. 299-307.

Pavía y Pavía, Francisco de Paula. Galería biográfica de los generales de Marina, jefes y personajes notables que figuraron en la misma corporación desde 1700 a 1868. I. Madrid: Imprenta de José López, 1873.

PETER, Jean. Vauban et Toulon. Histoire de la construction d'un port-arsenal sous Louis XIV. Paris: Economica, 1994.

PeTER, Jean. Le port et l'arsenal de Toulon sous Louis XIV. Paris: Economica, 1996.

«Representación hecha al Sr. D. Fernando el VI por su ministro el marqués de la Ensenada proponiendo medios para el adelantamiento de la monarquía y buen gobierno de ella». Revista del Semanario Erudito, Madrid, 1788, XII, pp. 267-268.

ROBERTSON, Ian. Los curiosos impertinentes. Viajeros ingleses por España desde la accesión de Carlos III hasta 1855. Barcelona: Serbal, 1988.

Rodríguez-Villasante Prieto, Juan Antonio. Tecnología y arte de la ilustración. La arquitectura e ingeniería de Sánchez Bort en la obra pública, la industria y los arsenales de Marina. Pontedeume: Asamblea Amistosa Literaria, 1988.

Rodríguez-Villasante Prieto, Juan Antonio. La obsesión por el orden académico. El arsenal de Ferrol. Madrid: Ministerio de Defensa, 2011.

SAmBricio, Carlos. La arquitectura española de la Ilustración. Madrid: Consejo Superior de los Colegios de Arquitectos de España, 1986.

SAmbricio, Carlos. Territorio y ciudad en la España de la Ilustración, 2 vols. Madrid: Ministerio de Obras Públicas y Transportes, 1991. 
SANZ, Miguel. Breve noticia de la vida del Excmo. Sr. D. Jorge Juan y Santacilia, reducida a los hechos de sus comisiones, obras y virtudes que a instancia de sus apasionados presenta al público su secretario. Madrid: Museo Naval, 1973.

SARALEGUI y MEDina, Leandro. Efemérides ferrolanas. Madrid, 1904.

Vigo Trasancos, Alfredo. Arquitectura y urbanismo en el Ferrol del siglo XVIII. Santiago: Colegio Oficial de Arquitectos de Galicia, 1984.

Vigo Trasancos, Alfredo. «El arquitecto-ingeniero Julián Sánchez Bort. Perfil biográfico y obra en Galicia». Cuadernos de Estudios Gallegos, 1984-85, XXXV, pp. 501-525.

VIGO TRASANCOS, Alfredo. «Los tratados de arquitectura de Belidor, Briseux y D'Aviler en la formación de los ingenieros militares: el ejemplo de la Sala de Armas del arsenal de Ferrol». En Jubilatio. Homenaje de la Facultad de Geografia e Historia a los profesores D. Manuel Lucas Álvarez y D. Ángel Rodríguez González, t. II. Santiago: Servicio de Publicaciones e Intercambio Científico de la Universidad de Santiago de Compostela, 1987, pp. 669-680.

Vigo Trasancos, Alfredo. «Julián Sánchez Bort». En Artistas Galegos. Arquitectos (da Ilustración ó Eclecticismo). Vigo: Nova Galicia Edicións, 2003, pp. 62-83.

Vigo Trasancos, Alfredo. A Coruña y el siglo de las luces. La construcción de una ciudad de comercio (1700-1808). Santiago: Servicio de Publicaciones de las Universidades de Santiago de Compostela y A Coruña, 2007.

Vigo Trasancos, Alfredo. "La "Casa del Rey" en la que vive el comandante general del Departamento Marítimo de Ferrol. Símbolo urbano y nudo urbano de la nueva ciudad dieciochesca (1751-1768)». Minius, 2011, n. ${ }^{\circ}$ 19, pp. 155-177.

Vigo Trasancos, Alfredo (dir.). Galicia y el siglo XVIII. Planos y dibujos de arquitectura y urbanismo (1701-1800). A Coruña: Fundación Barrié, 2011.

Vigo Trasancos, Alfredo. "Los ingenieros de Marina y el Reino de Galicia (1754-1800)». En García Hurtado, Manuel Reyes (ed.). La armada española en el siglo XVIII. Ciencia, hombres y barcos. Madrid: Sílex, 2012, pp. 67-100.

Vigo Trasancos, Alfredo. «Marte y Mercurio unidos por Hércules. El sueño ilustrado de un gran puerto hispano-indiano en el Golfo de los Ártabros (1720-1788)». En Actas del XVIII Congreso del C.E.H.A. Mirando a Clío. El arte español como espejo de su historia, III. Santiago, 2012, pp. 1730-1751.

Vigo Trasancos, Alfredo y Mera Álvarez, Irene. Ferrol y las defensas del puerto de guerra del rey. La Edad Moderna, 1500-1800. Ferrol: Autoridad Portuaria, 2008.

\section{RECURSOS DE ORDENADOR}

http://www.todoababor.es/vida_barcos/nav.htm. 